\title{
An investigation of the ways in which public health nutrition policy and practices can address climate change
}

\author{
Heidi Sulda ${ }^{1}$, John Coveney ${ }^{2, *}$ and Michael Bentley ${ }^{3}$ \\ ${ }^{1}$ Southern Primary Health Noarlunga Village, PO Box 437, Noarlunga Centre, South Australia 5168, Australia: \\ ${ }^{2}$ Department of Public Health, Flinders University, GPO Box 2100, Adelaide, South Australia 5001, Australia: \\ ${ }^{3}$ South Australian Community Health Research Unit, Department of Public Health, Flinders University, GPO Box \\ 2100, Adelaide, South Australia 5001, Australia
}

Submitted 19 August 2008: Accepted 10 March 2009: First published online 23 June 2009

\begin{abstract}
Objective: To develop a framework to guide action in the public health nutrition workforce to develop policies and practices addressing factors contributing to climate change.

Design: Action/consultative research.

Setting: Interviews - South Australia, questionnaire - Australia.

Subjects: Interviews - key informants ( $n$ 6) were from various government, academic and non-government positions, invited through email. Questionnaire participants were members of the public health nutrition workforce ( $n$ 186), recruited to the study through emails from public health nutrition contacts for each State in Australia (with the exception of South Australia).

Results: Support by participants for climate change as a valid role for dietitians and nutritionists was high (78\%). However, climate change was ranked low against other public health nutrition priorities. Support of participants to conduct programmes to address climate change from professional and work organisations was low. The final framework developed included elements of advocacy/ lobbying, policy, professional recognition/support, organisational support, knowledge/skills, partnerships and programmes.

Conclusions: This research demonstrates a need for public health nutrition to address climate change, which requires support by organisations, policy, improved knowledge and increased professional development opportunities.
\end{abstract}

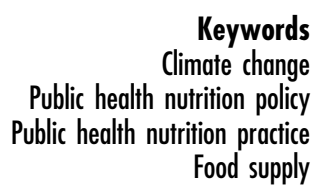

Keywords

rition practice

Food supply
The relationship between climate change and the food supply is complex. There is increasing evidence that climate change will impact on primary food production, e.g. agriculture. Evidence also exists that current food production and distribution systems release greenhouse gases $^{(1)}$ and thus contribute to climate change. This has led to consideration of three important issues in relation to climate change and the food supply. The first is adaptation: how can the current food supply adapt to a warming environment? The second is mitigation: how can current food production methods limit greenhouse gas emissions? The third is vulnerability: how will the effects of climate change on the food supply affect those who are already socially and economically disadvantaged, and how might this be addressed? Public health nutrition is concerned with the provision of a safe, affordable and accessible food supply, therefore climate change raises important issues for public health nutrition practice.

While the present research focuses on climate change in Australia, the issues addressed as well as the framework developed are easily applied to other arid countries that are likely to experience similar problems.

\section{Changes in climate and effects on the food supply}

When estimated as a trend of the past century, global mean surface temperature has risen by $0.74^{\circ} \mathrm{C}$ since $1906^{(2)}$. Findings of the Commonwealth Scientific and Industrial Research Organisation (CSIRO) investigating Australian climate change are similar, reporting that the continental average temperature has risen by $0 \cdot 7^{\circ} \mathrm{C}$ from 1910 to $1999^{(3)}$. The majority of this change occurred after $1950^{(3)}$. In Australia, it is projected that an average temperature increase of between 0.4 and $2 \cdot 0^{\circ} \mathrm{C}$ will occur over most of the country by 2030 , with slightly less warming in some coastal regions and Tasmania, and more warming possible in the north-west ${ }^{(3)}$.

Changes in climate have many impacts on the environment. The predicted impact on rainfall in Australia is 
varied $^{(4)}$ with a bias towards a decrease in rainfall in the south-west, parts of the south-east and Queensland, with that decrease more pronounced in winter and spring. Other climate change impacts may include increased evaporation and increases in the frequency of oceanic storm surges, gales, flooding rains and tropical cyclones ${ }^{(4)}$. All of these impacts are likely to have a negative influence on Australia's agricultural system and thus the food supply.

Predicted outcomes for agriculture include poor crop yields ${ }^{(5-12)}$, increased diseases and stress on livestock ${ }^{(13-15)}$, damage to the habitats of some species of fish ${ }^{(14,16)}$ and increased pest damage in fruit ${ }^{(17)}$. Moreover, the majority of the above-mentioned papers conclude that the ability for the agricultural industry to adapt to climate change is limited at the moment due to a lack of strong evidence to support strategies. While many researchers have studied the effects of climate change, few present adaptation strategies and even fewer recommendations are based on evidence.

\section{Impact of the food supply on climate change}

The food supply itself has a large impact on greenhouse gas emissions and therefore on climate change. Agricultural processes are the second largest source of greenhouse gas emissions in the Australian economy and accounted for $16 \%$ of Australia's net national emissions in $2005^{(1)}$. The sources of agriculture emissions are well known through the heavy use of fossil fuels within the industry, but also include enteric fermentation in livestock, manure management, rice cultivation, agricultural soils, prescribed burning of savannahs and field burning of agricultural residues ${ }^{(1)}$. Gas emissions from the livestock sector have the largest impact ${ }^{(1)}$. Options to mitigate climate change through reductions of greenhouse gas emissions are also limited due to a lack of evidence.

In Australia, and no doubt other countries with similar climates, climate change has the potential to decrease the quality, availability and variety of the food supply. Decreased grain nitrogen content due to climate change may make wheat less suitable for use in pasta and bread making ${ }^{(18)}$. If climate change results in poor live weight gain $^{(19)}$ in livestock, this may lead to poorer-quality meat products in the food supply. Potential pest damage to fruit under climate change ${ }^{(17)}$ may result in poorer-quality fruit being sold as the only alternative. All of these potential impacts on the food supply may lead to decreased quality, decreased availability and/or increased price.

Economically disadvantaged groups are generally those most at risk of lifestyle diseases such as diabetes and $\mathrm{CVD}^{(20)}$. There is evidence that the lower the cost of a diet, the higher the energy density ${ }^{(20,21)}$. If the prices of healthy foods increase under climate change, disadvantaged groups may not afford them and hence turn to less expensive but unhealthy foods, thus increasing their risk of lifestyle disease.
Vulnerability due to climate change has implications between countries with regard to economically disadvantaged groups. For example, actions in Australia might increase vulnerability overseas if mitigation options to reduce transport end up decreasing imports, thereby negatively impacting on developing countries in the longer term.

Ensuring equity is a primary health-care principle and therefore underpins public health nutrition practice. Throughout the world, vulnerable and socially disadvantaged people have less access to health resources, get sicker and die earlier than people in more privileged social positions ${ }^{(22)}$. These gaps are growing in spite of an era of unprecedented global wealth, knowledge and health awareness ${ }^{(22)}$. Climate change impacts on the food supply have the potential to increase these gaps and negatively affect equity; therefore this issue requires significant involvement of public health nutrition. In order to address the social determinants of health, nutritionists must have the necessary knowledge and skills to address environmental and social conditions that affect food and health ${ }^{(23)}$. This includes knowledge and skills associated with climate change.

\section{The role of public health nutrition}

Nutritionists have a responsibility to promote a food supply that is not only nutritious but also sustainable. Public health nutritionists have been involved in the debate concerning the environment and the food supply for many years; however, the focus has until recently been on ecological sustainability of the food supply. Gussow and Clancy ${ }^{(24)}$ developed the 'Dietary Guidelines for Sustainability' which sought to encourage eating patterns more in sympathy with environmental imperatives. Other work has explored the issues of food variety and biodiversity in a changing environment, coining the term 'econutrition' ${ }^{(25)}$. Sustain, the UK organisation for sustainable food and farming, and the US Center for Science in the Public Interest are examples of organisations exploring and addressing ecological public health nutrition. The American Dietetic Association has released a position statement 'Food and Nutrition Professionals Can Implement Practices to Conserve Natural Resources and Support Ecological Sustainability'(26).

There is limited Australian or overseas information on the role of public health nutritionists in addressing climate change. Some have suggested incorporating environmental messages into Australia's nutrition messages such as 'Go for 2 and 5' as a way for nutritionists to address climate change ${ }^{(27)}$. Others suggest encouraging locally produced, less processed foods ${ }^{(26,28)}$, facilitating 'buy local' campaigns ${ }^{(26)}$, learning about local food systems and imparting this knowledge to the public ${ }^{(29)}$, and promoting seasonal foods to decrease reliance on imported foods ${ }^{(28,29)}$. These and other actions are best undertaken through a coordinated approach as part of alliances, 
coalitions and networks, including food policy councils $^{(29)}$. Coordinated approaches to bring about change usually require the development of strategies, or frameworks, which steer action towards defined goals.

One of the most influential frameworks in health promotion is the Ottawa Charter, which was developed as a template for action. The Ottawa Charter incorporates both indirect and direct actions. Direct actions are those that are able to be undertaken by health professionals at an individual level, whereas indirect actions are those that are undertaken through large-scale action such as policy change. Frameworks can also assist in instigating organisational change. For example, Mitchell ${ }^{(30)}$ developed a framework to address equity in health promotion and notes the usefulness in providing structure for thinking about and understanding factors influencing an issue. The coordinated effort to address climate change is likely to benefit from the development of a framework to inform policy and practice in public health nutrition. This is highlighted by Johnson and Paton's view that 'frameworks are also useful when working with change from outside an entrenched power base ${ }^{,(31)}$.

There are gaps in the literature regarding public health nutritionists' opinions, motivation and perception of the importance of addressing climate change. Information is also lacking on the types of nutrition programmes required to address climate change in practice, as well as the knowledge, skills, support, partnerships, infrastructure, professional recognition and policies needed in order for them to be conducted. The purpose of the present research was to develop a framework to guide action in the public health nutrition workforce to develop policies and practices addressing factors contributing to climate change. The objectives were to:

1. Identify the relationships between climate change, food supply and food choice.

2. Examine the potential role of the public health nutrition workforce to address climate change.

3. Assess public health nutritionists' views and expectations about the feasibility of adopting policies and practices that would address climate change.

4. Formulate a framework towards a public health nutrition response to address factors contributing to climate change.

Throughout the remainder of the paper the public health nutrition profession and public health nutritionists are referred to as the PHN workforce and PHNs, respectively. The latter title includes public health nutritionists and dietitians, community dietitians and nutritionists, and other public health nutrition positions (such as health promotion officers).

\section{Methods}

The current study was conducted in Adelaide, South Australia in 2007. Ethics approval for the study was gained from the Flinders University Social and Behavioural Research Ethics Committee. Methodologically, the study was based on an action research approach which requires the development of ideas, strategies and areas of action which are then confirmed or adapted with input from stakeholder groups and are refined through a succession of cycles ${ }^{(34)}$.

The research was undertaken in two phases. Phase 1 used a literature review to draft an initial framework for public health nutrition action addressing climate change. The initial framework was assessed for validity in interviews with a range of key informants with expertise in climate change and the PHN workforce. Phase 2 tested the feasibility of the resulting framework through a questionnaire completed by PHNs across Australia. The final framework was developed in light of the results obtained from the questionnaire.

\section{Phase 1}

\section{Literature review}

A review of the recent literature (1995 to date) was conducted to identify the relationship between climate change, food supply and health, and also the potential role of PHNs in addressing climate change. Keywords used were 'climate change' or 'global warming' with 'food security', 'food system', 'food sustainability' or 'food supply'. Articles addressing the review purpose were obtained in full. Appropriate articles cited within chosen articles were also included. Australian research was used where possible, drawing on global research when required.

\section{Framework and questionnaire development}

On the basis of the literature review an initial framework was drafted. The framework comprised key elements concerning direct and indirect action by PHNs. In order to field-test the use, validity and appropriateness of the framework, a questionnaire was developed to assess PHNs' views and support for the framework.

\section{Interviews}

Six key informants were interviewed. The informants were chosen because of their seniority and experience in environmental and/or public health nutrition issues. They came from a variety of backgrounds such as a university department of nutrition and dietetics, the SA Centre for Health Promotion, the South Australian Department of the Premier and Cabinet, SA Greens and the South Australian Department for Environment and Heritage. Respondents were interviewed about key elements of the framework as they appeared in the questionnaire, and their opinion of the role and capacity of public health nutrition in addressing climate change.

\section{Phase 2}

\section{Questionnaire}

On the basis of Phase 1 a questionnaire was developed to test PHNs' responses to key components of the framework. 
The questionnaire was pilot-tested with two independent dietitians for face validity. The final questionnaire included thirty-one items with sections on awareness and knowledge of climate change, current programmes addressing climate change, barriers to involvement in and opinions about climate change, and demographics. The questionnaire was entered on to a web-based server, SurveyMonkey.com, which created a web link for the questionnaire. This web link was distributed to dietitians and nutritionists, via email, to contact persons for the Public Health Nutrition Network in each State (with the exception of South Australia), the Dietitians' Association of Australia's Public Health Nutrition list-serve and the Nut-Net list-serve, with instructions to distribute to all members of each network/ list-serve. Questionnaire participants were instructed to send the link to others who may not have received the questionnaire. In South Australia the questionnaire was distributed by the first author at a South Australian Nutrition Network meeting.

\section{Final framework development}

Themes taken from the questionnaire were ranked from most common to least common, and the most common themes were used to further develop the framework. Percentages from closed questions were listed and incorporated into the framework in a similar way. Thus the final framework was rebuilt using the results from the questionnaire.

\section{Statistical analysis and sample size}

Basic descriptive statistical analysis was performed on closed-ended questions; this was conducted via the SurveyMonkey.com server. Theme analysis was performed manually for open-ended questions in the questionnaire. This was repeated by a researcher independent to the project and then cross-checked to ensure congruence. A summary of the stakeholder interviews was developed manually.

The sample size the questionnaire reached through our methods was estimated to be 276 , based on work conducted by Hughes in $2004^{(33)}$. Thus the estimated response rate of the questionnaire was in the region of $67 \%(186 / 276)$.

\section{Results}

\section{Pbase 1}

The key informant interviews identified a number of links between climate change, food and health in Australia (in particular, the impact that the food supply can have on climate change). The informants acknowledged the need for policies and practices to address climate change and suggested roles that PHNs could play (e.g. advocacy, lobbying and raising awareness). They also acknowledged the barriers faced by PHNs in addressing climate change (poor knowledge, uncertainty and the low priority climate change has within organisations).
A draft framework was developed based on the literature review and on common issues consistently raised in interviews with key informants. The framework recognises the need in health practice for direct and indirect action. It comprises several key areas:

1. Professional recognition of engagement in climate change issues.

2. Organisational support/infrastructure for climate change engagement.

3. Partnerships and advocacy to address climate change.

4. Knowledge and skills about climate change.

5. Adaptation responses of the food supply to climate change.

6. Mitigation responses to reduce the impact of the food supply on climate change.

\section{Phase 2}

Study sample

The study sample refers to questionnaire participants. Table 1 lists a summary of the responses to the questionnaire. The gender distribution was predominantly female $(91 \%)$. Over three-quarters of the participants worked as community dietitians, community nutritionists or public health nutritionists. The distribution of participants across State of residence was similar to that of Hughes ${ }^{(33)}$, the exception being that the present study had a higher proportion of participants from Queensland (20\%v. 10\%) and a lower proportion of participants from Western Australia (8\% v. 16\%).

\section{Current situation}

Participants rated climate change as a very important issue, one about which they are very concerned. On a scale of 1 to 10 , with $1=$ extremely unimportant/unconcerned and $10=$ extremely important/concerned, more than $90 \%$ rated climate change as 7 or higher. There was overwhelming support (78\%) for climate change as a valid issue for dietitians and nutritionists. However, when asked to rank climate change against three other public health nutrition priorities (food security, overweight/ obesity, chronic disease), climate change was most commonly ranked fourth (lowest priority). Further data suggested that the low ranking of climate change was in fact an organisational, not personal, priority.

When asked about food-based programmes or interventions addressing climate change, $25 \%$ reported 'yes' to knowing of current programmes and 14\% reported 'yes' to currently conducting them. However, those who knew of current programmes reported that none were run with the express purpose of addressing climate change.

\section{Final framework}

The final framework (Fig. 1) developed from the current research is divided into indirect and direct actions. Advocacy is the starting point in the framework to promote 
Table 1 Summary of responses to the questionnaire distributed to PHNs in Phase 2

Q1. To what extent do you think you are aware of climate change issues generally?

Q2. On a scale of 1 to 10 (where $1=$ extremely unimportant and $10=$ extremely important) how important do you think climate change is as an issue for Australia?

Q3. On a scale of 1 to 10 (where $1=$ extremely unimportant and $10=$ extremely important) how concerned are you about climate change?

Q4. Where did/do you get information on climate change?

Q5. To what extent are you aware of the relationship between climate change and the food supply?

Q6. Which of the following food groups do you think will be impacted by climate change?

Q7. Which of the following groups do you think will experience a change in cost due to climate change?

Q8. Which of the following groups do you think will experience a change in variety due to climate change?

Q9. Which of the following groups do you think will experience a change in availability due to climate change?

Q10. To what extent are you aware of the ways that the food supply impacts on climate change?

Q11. If you are aware or very aware of the ways in which the above aspects impact on climate change, in which ways do the following aspects of the food supply impact on climate change?

Q12. Do you know of any food-based programmes or interventions (past or present) to address climate change?

Q13. Are you or your work organisation currently running any food-based programmes or interventions to address climate change?

Q14. In order of importance to your work as a nutritionist/dietitian (where 1 is the most important), how would you rank the following issues?

Q15. If 'other' above, please specify.

Q16. Do you have any comments about your rank order?

Q17. In your view, would efforts to address climate change be a valid role for dietitians and nutritionists?

Q18. If yes to the above question, please tick all roles you believe to be valid.

Q19. To what extent would you be motivated to incorporate climate change strategies in your work?

Q20. To what extent do you agree or disagree that your professional organisation (e.g. DAA, PHAA, AHPA) should take up the role of addressing climate change?

Q21. To what extent do you agree or disagree that your professional organisation (e.g. DAA, PHAA, AHPA) provides you with the following, with regard to climate change?

Q22. To what extent do you agree or disagree that public health nutritionists or community dietitians should run food-based programmes or interventions to address climate change?

Q23. In your view would your work organisation support you to conduct food-based programmes or interventions to address climate change?

Q24. To what extent do you agree or disagree that your work organisation provides you with the following, with regard to climate change?
Aware or very aware: $95 \cdot 7 \%$

Mean rating: $9 \cdot 0$

Mean rating: $8 \cdot 5$

Top five sources: media (94.1\%); magazines (50.5\%); Internet $(47.3 \%)$; professionals $(44.1 \%)$; books $(34.9 \%)$

Aware or very aware: $89.0 \%$

Vegetables (98.2\%); fruit (97.7\%); breads and cereals (95.3\%); meat $(93.6 \%)$; dairy foods $(90.1 \%)$; meat alternatives, e.g. beans, lentils, eggs ( $85.4 \%)$; vegetable oils $(70.8 \%)$; sugar $(70.2 \%)$; animal fat $(58.5 \%)$

Main response: increased cost in vegetables $(98.2 \%)$; fruit $(97.6 \%)$; meat $(93.5 \%)$; breads and cereals $(92.3 \%)$; dairy foods $(91 \cdot 1 \%)$; meat alternatives, e.g. beans, lentils, eggs $(79.6 \%)$; vegetable oils $(61 \cdot 6 \%)$; sugar $(54 \cdot 7 \%)$; animal fat $(51.9 \%)$

Main responses: decreased variety in fruit $(84.3 \%)$; vegetables $(83.3 \%)$; breads and cereals $(44.2 \%)$; meat alternatives, e.g. beans, lentils, eggs (36.6\%); no change in sugar (59.1\%); dairy foods $(49.1 \%)$; animal fat $(46.5 \%)$; meat $(38.7 \%)$; vegetable oils $(31 \cdot 7 \%)$

Main response: decreased availability of fruit (94.6\%); vegetables $(94.0 \%)$; meat $(72 \cdot 6 \%)$; breads and cereals $(68.3 \%)$; dairy foods $(64.2 \%)$; meat alternatives, e.g. beans, lentils, eggs $(61.2 \%)$; vegetable oils $(41.6 \%)$; sugar $(37 \cdot 1 \%)$; animal fat $(35.0 \%)$

Aware or very aware of: land use (86.2\%); food miles (79.9\%); food processing $(79.6 \%)$; food packaging $(79.5 \%)$; refrigeration $(73.6 \%)$; ruminants $(67.7 \%)$; fish farms $(34.6 \%)$

Multiple and varied responses to land use, ruminants, food miles; food processing, food packaging, refrigeration, fish farms

Yes $(25.3 \%)$; no $(74.7 \%)$

Yes (14.3\%); no (85.7\%)

Mean ratings: overweight and obesity $=2 \cdot 1$; food security $=2 \cdot 3$; chronic disease, e.g. type 2 diabetes $=2 \cdot 5$; climate change $=3 \cdot 2$; other $=3 \cdot 2$

A variety of responses including child nutrition, breast-feeding, Aboriginal health

A number of respondents indicated the ranking reflected organisational priorities

Yes $(77.6 \%)$; no (4.8\%); don't know (17.7\%)

Advocacy (91.5\%); education - public (89.7\%); education professionals $(84.6 \%)$; lobbying $(78.6 \%)$; other $(23.1 \%)$

Motivated or very motivated: $91 \cdot 1 \%$

Agree or strongly agree: $83.7 \%$

Disagree or strongly disagree: awareness/updates (59.7\%); professional development (56.8\%); resources $(66 \cdot 2 \%)$; recognition for addressing climate change $(59.7 \%)$

Agree or strongly agree: $71 \cdot 6 \%$

Yes (34.8\%); no (17.7\%); don’t know (47.5\%)

Disagree or strongly disagree: awareness/updates (61.2\%); professional development (63.3\%); resources (69.3\%); recognition for addressing climate change $(59 \cdot 1 \%)$ 
Table 1 Continued

\begin{tabular}{|c|c|}
\hline Question & Summary of response \\
\hline $\begin{array}{l}\text { Q25. In terms of your work, do you think there would be a need to } \\
\text { develop partnerships in order for you to conduct food-based } \\
\text { programmes or interventions to address climate change? }\end{array}$ & Yes $(93.4 \%) ;$ no $(6.6 \%)$ \\
\hline $\begin{array}{l}\text { Q26. In your view, what policies need to be in place to support } \\
\text { you to carry out programmes or interventions to address } \\
\text { climate change? }\end{array}$ & $\begin{array}{l}\text { Most common responses }(n) \text { : government policy (21); recognition } \\
\text { as core business (7); link nutritional and environmental policy } \\
\text { (6); work unit/organisation environmental policies (5); funding } \\
\text { for interventions (5) }\end{array}$ \\
\hline $\begin{array}{l}\text { Q27. In your view, what skills would you require in order to run } \\
\text { food-based programmes or interventions that address climate } \\
\text { change? }\end{array}$ & $\begin{array}{l}\text { Most common responses }(n) \text { : knowledge - evidence base/ } \\
\text { research (32); knowledge - general (14); knowledge - effective } \\
\text { programmes (9); professional development (9); political } \\
\text { lobbying/advocacy skills (6) }\end{array}$ \\
\hline $\begin{array}{l}\text { Q28. In your view, what should public health nutritionists be } \\
\text { recommending to the public in order to reduce the adverse } \\
\text { effects of climate change on food supply? }\end{array}$ & $\begin{array}{l}\text { Most common responses }(n) \text { : purchase local (48); grow own food } \\
\text { (27); whole/unprocessed foods (26); decrease meat/ruminant } \\
\text { consumption (24); decrease packaged foods (23); seasonal } \\
\text { foods (22) }\end{array}$ \\
\hline Q29. Do you have any other comments? & A number of votes of thanks for the survey \\
\hline Q30. Age & Mean age: 33.9 years \\
\hline Q31. Sex & Female $(91 \cdot 1 \%)$; male $(8.9 \%)$ \\
\hline Q32. Organisation/company of employment & $\begin{array}{l}\text { Most work in government (departments or health services) and } \\
\text { non-government organisations }\end{array}$ \\
\hline Q33. Which title best describes your position? & $\begin{array}{l}\text { Community dietitian (38.8\%); community nutritionist }(13.4 \%) \text {; } \\
\text { public health nutritionist }(26.9 \%) \text {; other }(26.1 \%)\end{array}$ \\
\hline Q34. Years in position & Mean number of years: $4 \cdot 7$ \\
\hline Q35. Please indicate the state you reside in. & $\begin{array}{l}\text { NSW (22.7\%); VIC (26.5\%); QLD (20.5\%); SA (11.4\%); WA } \\
\text { (8.3\%); NT (6.1\%); TAS (3.0\%); ACT (1.5\%) }\end{array}$ \\
\hline
\end{tabular}

PHNs, public health nutritionists and dietitians, community dietitians and nutritionists, and other public health nutrition positions (e.g. health promotion officers); DAA, Dietitians' Association of Australia; PHAA, Public Health Association of Australia; AHPA, Australian Health Promotion Association; NSW, New South Wales; VIC, Victoria; QLD, Queensland; SA, South Australia; WA, Western Australia; NT, Northern Territory; TAS, Tasmania; ACT, Australian Capital Territory.

the development of nutrition policy including climate change. Advocacy to workplace and professional organisations is also needed. Indirect actions follow in the areas of policy, work and professional organisations. This will lead to direct actions within public health nutrition to increase skills and knowledge, finally leading to PHNs conducting programmes to address climate change.

The elements of the final framework are discussed more fully below.

Advocacy/lobbying. The advocacy/lobbying element of the framework refers to the participation by PHNs in alliances, coalitions and networks to build political and professional support for addressing climate change. Of the $78 \%$ of participants reporting addressing climate change as a valid role for PHNs ( $n$ 117), $92 \%$ reported advocacy and 79\% reported lobbying as valid roles. Public health nutrition advocacy to addressing climate change was a strong theme presented in key informant interviews. These results combined provide support for the suggestion under the Advocacy/lobbying section of the framework (see Fig. 1).

Policy. This element refers to the development of State and National Government policy that links nutritional and environmental policy, includes climate change as core business area for nutrition and dietetics, and allocates funding to allow PHNs to address climate change within their work roles.

Professional recognition/support. Professional recognition/support is included in the framework with suggestions to increase recognition and support for addressing climate change, through increased access to resources, professional development and information regarding climate change. The majority (84\%) of participants 'agreed' or 'strongly agreed' their professional organisation should take up the role of addressing climate change. There was strong support in the stakeholder interviews for professional associations to 'take up the issue' and 'lead the way'.

However, the majority reported to 'disagree' or 'strongly disagree' that professional organisations currently provide adequate support to address climate change. These results suggest the need for improved support by professional organisations in this area.

Organisational support. This element refers to the need for increased recognition and support for addressing climate change, through access to resources, professional development and information regarding climate change. When asked about work organisation support, 35\% of participants reported 'yes' (they would be supported) and $48 \%$ reported 'don't know'. This suggests that while PHNs in the field may want to address climate change, many may not due to uncertainty about the support they may or may not receive. It may also suggest that climate change is not on the agenda of many work organisations. As with professional organisations, the majority of participants believe their work organisation does not provide adequate support to address climate change; therefore increased support from work organisations was included in the framework. 


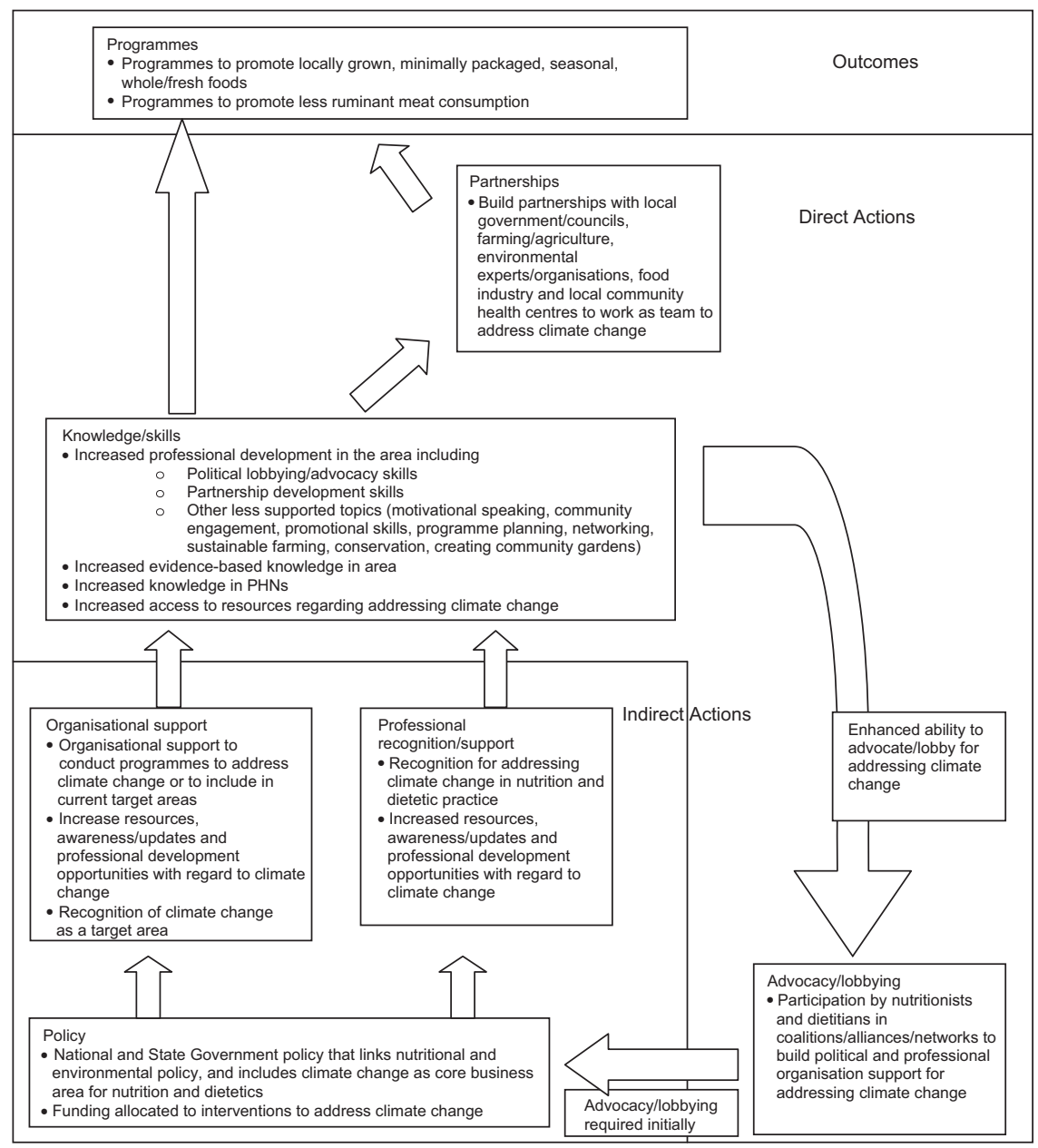

Fig. 1 Framework towards a public health nutrition response to climate change (PHNs are public health nutritionists and dietitians, community dietitians and nutritionists, and other public health nutrition positions, e.g. health promotion officers)

Knowledge/skills. This element includes suggestions to increase the knowledge base, professional development and access to resources on addressing climate change. Awareness of the relationship between climate change and the food supply was reported by the majority of participants, $89 \%$ of participants reported being either 'aware' or 'very aware'.

Knowledge-related themes were the most commonly reported skill required. Respondents expressed a need for more knowledge - and evidence from research - to assist them in running programmes addressing climate change. However, there was a discrepancy between the number of participants who reported having knowledge of the issue and those who were able to answer correctly questions about climate change in the questionnaire. This is perhaps not surprising considering that $94 \%$ of participants reported using media sources as the main source of information about climate change. These results provide strong support for the inclusion in the framework of increased evidence base, knowledge and resources to better inform PHNs about climate change.
Partnerships. This element refers to alliances required to be developed in order to address climate change. Development of partnerships was well supported, with 93\% of participants believing that partnerships needed to be developed in order to address climate change. The most common partnerships required were local councils, environmental experts/organisations, farming/agriculture/ local growers, the food production industry and local community health centres.

Programmes. The final element includes aspects of programmes to address climate change. The programme suggestions most commonly referred to concerned purchasing foods locally, promoting home-grown foods using whole/unprocessed foods, decreasing meat/ruminant consumption, decreasing packaged foods and using seasonal foods.

\section{Discussion}

The purpose of the present study was to develop a framework to guide public health nutrition efforts to address 
climate change. The study used an action research approach, which aims to involve constituents in the testing, development and refining of actions to address problems ${ }^{(32)}$.

This is the first Australian study in the area, and the first to research public health nutrition and climate change together. The framework was developed to provide a starting point for the public health nutrition response to climate change. It was developed heuristically, i.e. adapting to the evidence available throughout the study. One example of this adaptation is the advocacy 'loop' present in the final framework (Fig. 1). Advocacy was initially within the main body of the framework. As data were collected, it was found that while advocacy is required initially, many $\mathrm{PHNs}$ reported the need for better advocacy skills. The loop was created to describe the following process: as PHNs advocate for climate change, policy is developed, more knowledge and resources will become available, more opportunities to develop advocacy skills in the area will arise and the ability to advocate will increase, thus allowing more PHNs to advocate for climate change.

\section{Implications}

The results of the study suggest a strong need for policy concerning climate change and the food supply. State health departments are the largest employers of PHNs and provide the largest proportion of funding for these positions ${ }^{(33)}$. As the work within these departments is based on government policy, policy needs to be developed including climate change in order for PHNs to receive the support required to address climate change. Increased support and funding will allow more opportunities to research this area.

There is currently a disconnection between what PHNs want to do about climate change and what they can do within the positions they hold. Importance and concern for climate change is rated highly, as is motivation to address climate change. The majority agreed that PHNs should address climate change. However, when ranked against other priorities, climate change is rated as the least important priority, and many are not conducting programmes to address climate change and do not know of any programmes addressing climate change. The scope for PHNs to address climate change is likely to improve if policy is developed to include addressing climate change as a part of core business for PHNs.

Given that this is the first study to examine public health nutrition and climate change, it is difficult to compare the results with current literature. However, the need for advocacy is found in other areas of the public health nutrition literature ${ }^{(29,34-36)}$, as is the recommendation for health policy including climate change ${ }^{(26,37)}$. The partnerships required to be developed and the aspects of programmes to be conducted are also consistent with the literature ${ }^{(26-29,37)}$. Thus the results of the current research support, and are supported by, work on change in public health nutrition.

\section{Study limitations}

The sample population and response rate used in this study were estimated based on work conducted by Hughes in 2004 to enumerate the PHN workforce ${ }^{(33)}$. State distributions of participants were compared with the latter work and found to be similar. We were unable to compare job titles as different categories were used in the present study. Basing these calculations on previous work has limitations. First, as the earlier work was conducted in 2004, it is expected that the PHN workforce has expanded since then; therefore the response rate calculated in our study is likely to be overestimated. Second, statistical analysis of the ability of our sample to represent the population was not conducted due to the age of the data. Therefore the current research may not represent the PHN workforce population. Lastly, the study is limited by the accuracy of Hughes' work. Hughes reports methodological issues which limit the accuracy of the enumeration $^{(33)}$.

The interviews included only a limited sample of representatives from the possible broader range of food and health systems sectors. This may have limited the nomination of concepts in the present study and the framework's ability to sufficiently represent the views of other players in the food system. Future research could be done in this area to gain a broader understanding of the topic.

\section{Study strengths}

The study strengths are that the framework development was based on a variety of data: literature review; questionnaire; and key informant interviews. The questionnaire used was distributed electronically and therefore required minimal effort for participants to complete. Importantly, the resulting framework is evidence-based; it has been developed after input from the PHN workforce and therefore represents the level and kinds of action which are likely to be effective for PHNs in addressing climate change.

There is an evident need for further research in the area. In order for PHNs to determine the target populations for programmes, more research into the groups most vulnerable to the impacts of climate change is required. Research into climate change impacts that are region-specific are required in order for adaptation programmes to be conducted, as impacts will differ between locations. As programmes are conducted, reports need to be developed detailing effective programmes and effective aspects of programmes. Finally, as more research evidence becomes available, the framework will need to be adapted accordingly. 


\section{Conclusion}

The current research has demonstrated a need for public health nutrition to address climate change. This need requires support by organisations, policy, improved knowledge and increased professional development opportunities. The research has also demonstrated the ability of frameworks in health promotion and health equity to be adapted for action in other health areas.

\section{Acknowledgements}

Sources of funding: None. Conflict of interest declaration: None declared. Author contributions: H.S. carried out the interviews, conducted the questionnaire and drafted the initial version of the manuscript. J.C. conceived and managed the research project; co-supervised H.S. (with M.B.); assisted with the qualitative analysis; read all versions of the manuscripts and revised sections significantly. M.B. co-supervised H.S. (with J.C.); assisted with the survey analysis; read all drafts and commented on them; and summarised as text data that were in tabular form. Acknowledgements: The authors would like to acknowledge the contribution of the dietitians and informants who took part in the study.

\section{References}

1. Department of the Environment and Water Resources (2007) National Greenhouse Gas Inventory 2005. Canberra: Australian Greenhouse Office.

2. Intergovernmental Panel on Climate Change (2007) Summary for Policymakers. Cambridge/New York: IPCC.

3. Commonwealth Scientific and Industrial Research Organisation (2001) Climate Change Projections for Australia. Victoria: CSIRO.

4. Commonwealth Scientific and Industrial Research Organisation (2001) Climate Change Impacts for Australia. Victoria: CSIRO.

5. Howden SM \& Jones R (2001) Costs and Benefits of $\mathrm{CO}_{2}$ Increase and Climate Change on the Australian Wheat Industry. Canberra: Department of Climate Change.

6. Howden SM, Moore JL, McKeon GM \& Carter JO (2001) Global change and the mulga woodlands of southwest Queensland: greenhouse gas emissions, impacts, and adaptation. Environ Int 27, 161-166.

7. Howden SM, Reyenga PJ \& Meinke H (1999) Fertiliser Management of Wheat Crops Under Global Change. Canberra: CSIRO Wildlife and Ecology.

8. Reyenga PJ, Howden SM, Meinke $\mathrm{H}$ \& McKeon GM (1997) Global change impacts on wheat cropping in the Burnett Region of Queensland: a simulation approach. In MODSIM 97, International Congress on Modelling and Simulation Proceedings, pp. 149-154. Canberra: Modelling and Simulation Society of Australia Inc.

9. Reyenga PJ, Howden SM, Meinke H \& McKeon GM (1999) Modelling global change impacts on wheat cropping in south-east Queensland, Australia. Environ Model Softw 14, 297-306.

10. van Ittersum MK, Howden SM \& Asseng S (2003) Sensitivity of productivity and deep drainage of wheat cropping systems in a Mediterranean environment to changes in $\mathrm{CO}_{2}$, temperature and precipitation. Agric Ecosyst Environ 97, 255-273.

11. Luo Q, Williams MAJ, Bellotti W \& Bryan B (2003) Quantitative and visual assessments of climate change impacts on South Australian wheat production. Agric Syst 77, 173-186.

12. Howden SM, Reyenga PJ \& Meinke H (1999) Mixed Wheat-Sorghum Cropping Systems in Eastern Australia Under Global Change. Canberra: CSIRO Wildlife and Ecology.

13. Howden SM \& Turnpenny J (1997) Modelling heat stress and water loss of beef cattle in subtropical Queensland under current climates and climate change. In MODSIM 97, International Congress on Modelling and Simulation Proceedings, pp. 1103-1108. Canberra: Modelling and Simulation Society of Australia Inc.

14. Department of the Environment and Water Resources (2005) Climate Change Risk and Vulnerability. Canberra: Australian Greenhouse Office.

15. White N, Suthherst RW, Hall N, Whish-Wilson N \& WhishWilson P (2003) The vulnerability of the Australian beef industry to impacts of the cattle tick under climate change. Climatic Change 61, 157-190.

16. Meynecke J-O, Lee SY, Duke NC \& Warnken J (2006) Effect of rainfall as a component of climate change on estuarine fish production in Queensland, Australia. In Salt marsh geomorphology: Physical and ecological effects on landform. Estuarine Coast Shelf Sci 69, 491-504.

17. Suthherst RW, Collyer BS \& Yonow T (2000) The vulnerability of Australian horticulture to the Queensland fruit fly, Bactrocera (Dacus) tryoni, under climate change. Aust J Agric Res 54, 467-480.

18. Pittock B (2003) Climate Change: An Australian Guide to the Science and Potential Impacts. Canberra: Australian Greenhouse Office.

19. Howden SM, McKeon GM, Meinke H, Entel M \& Flood N (2001) Impacts of climate change and climate variability on the competitiveness of wheat and beef cattle production in Emerald, north-east Australia. Environ Int 27, 155-160.

20. Drewnowski A \& Darmon N (2005) Food choices and diet cost: an economic analysis. J Nutr 135, 900-905.

21. Drewnowski A \& Darmon N (2005) The economics of obesity: dietary energy density and energy cost. Am J Clin Nutr 82, 1 Suppl., S265-S273.

22. Commission on Social Determinants of Health (2007) Achieving Health Equity: From Root Causes to Fair Outcomes. Geneva: Commission on Social Determinants of Health.

23. Cannon G \& Leizmann C (2005) The new nutrition science project. Public Health Nutr 8, 673-694.

24. Gussow JD \& Clancy KL (1986) Dietary guidelines for sustainability. J Nutr Educ 8, 1-5.

25. Wahlqvist ML \& Specht RL (1998) Food variety and biodiversity: econutrition. Asia Pac J Clin Nutr 7, 314-319.

26. American Dietetic Association (2007) Position of the American Dietetic Association: food and nutrition professionals can implement practices to conserve natural resources and support ecological sustainability. J Am Diet Assoc 107, 1033-1043.

27. Wallace J (2007) The sustainability benefits of a healthier diet. Public Health Bull 4, 15-17.

28. Storper B (2003) Moving toward healthful sustainable diets. Nutr Today 38, 57-59.

29. Peters J (1997) Community food systems: working toward a sustainable future. J Am Diet Assoc 97, 955-956.

30. Mitchell J (2007) An exploration of the development of an equity-focused conceptual framework for a regional health 
promotion service and its likely impact. DrPH Thesis, Flinders University.

31. Johnson A \& Paton K (2007) Health Promotion and Health Services, p. 182. Melbourne: Oxford University Press.

32. Baum F (2002) The New Public Health, 2nd ed. Melbourne: Oxford University Press.

33. Hughes R (2004) Enumerating and profiling the designated public health nutrition workforce in Australia. Nutr Diet 61, 162-171.
34. Stott R (2006) Contraction and convergence. Healthy response to climate change. BMJ 332, 1385-1387.

35. Lang $\mathrm{T}$ (2005) Food control or food democracy? Reengaging nutrition with society and the environment. Public Health Nutr 8, 730-737.

36. Harrison D (2006) Peak oil, climate change, public health and well-being. J R Soc Promot Health 126, 62-63.

37. Garnett T (2003) Wise Moves - Exploring the Relationship Between Food, Transport and $\mathrm{CO}_{2}$. London: Transport 2000. 